\title{
Distinct habitat types arise along a continuous hydrodynamic stress gradient due to interplay of competition and facilitation
}

\author{
Bregje K. van Wesenbeeck ${ }^{1,4, *}$, Caitlin M. Crain ${ }^{2,3}$, Andrew H. Altieri ${ }^{2}$, \\ Mark D. Bertness ${ }^{2}$ \\ ${ }^{1}$ Netherlands Institute of Ecology (NIOO-KNAW), Centre for Estuarine and Marine Ecology, PO Box 140, 4400 AC Yerseke, \\ The Netherlands \\ ${ }^{2}$ Department of Ecology and Evolutionary Biology, Brown University, Providence, Rhode Island 02912, USA \\ ${ }^{3}$ Present address: Long Marine Lab, University of California, Santa Cruz, California 95060, USA \\ ${ }^{4}$ Present address: WL Delft Hydraulics, PO Box 140, 2600 MH Delft, The Netherlands
}

\begin{abstract}
Though species interactions across local environmental gradients are well studied, the way in which species interactions shift between different habitats on a landscape scale has received less attention. We hypothesised that interactions among a suite of shoreline plant species shift across a hydrodynamic-exposure gradient, leading to generation of apparently distinct habitat types (e.g. bare cobble beaches, vegetated cobble beaches, fringing marshes and salt marshes). We examined hydrodynamic forcing and found that it was strongly correlated with shoreline habitat type. A transplant experiment revealed that all plants were rapidly crushed and abraded in bare cobble areas with high hydrodynamic energy and were out-competed by grasses in the low-energy salt marshes. Vegetated cobble beaches are inhabited by the largest amount of plant species under intermediate conditions, where hydrodynamic energy is sufficiently low to allow the establishment of the ecosystem engineer Spartina and sufficiently high to prevent the monopolisation of space by competitively dominant, but stress intolerant grasses. Experimentally reducing physical and biotic stresses (hydrodynamics and interspecific competition) on bare cobble beaches and salt marshes, respectively, enabled forbs to persist across the whole gradient. These results demonstrate that the outcome of interspecific interactions at landscape scales is driven by background physical conditions, and that this can result in the development of what are considered distinct habitats.
\end{abstract}

KEY WORDS: Interspecific interactions $\cdot$ Stress gradient $\cdot$ Salt marsh $\cdot$ Cobble beach $\cdot$ Intermediate disturbance hypothesis · Hydrodynamics

Resale or republication not permitted without written consent of the publisher

\section{INTRODUCTION}

How species interactions shift across environmental gradients has been a fruitful ecological inquiry. However, most studies have focused on single habitat types and/or small-scale gradients. Recent research has begun to scale-up and investigate shifting species interactions across landscape-scale gradients (e.g. alpine gradients, Callaway et al. 2002; estuarine salinity gradients, Crain et al. 2004). Despite this recent trend, the potential for shifting species interactions to result in what are traditionally considered distinct habitats has received considerably less attention.

Coastal shorelines are ideal systems for testing questions across large-scale environmental gradients, since stress conditions, such as hydrodynamic forcing or salinity, vary predictably. The biological communities of coastal habitats are relatively easy to manipulate, their community ecology has been extensively explored, and they are exposed to multiple environmental stressors, such as wave exposure, changes in salinity, and desiccation (Bertness et al. 2000). Shore- 
line geology and oceanography largely determine the degree to which coastal environments are exposed to these forms of stress in a predictable manner. For instance, exposed rocky headlands experience greater wind and hydrodynamic stress than nearby protected shores, while protected bays accrete sediments and form salt marshes (Allen 2000). In Narragansett Bay, Rhode Island, USA, coastal habitats include salt marshes, cobble beaches and rocky shore habitats that have each been well studied independently (e.g. Bertness 1999, Bruno 2000, Kennedy \& Bruno 2000). Thus, community ecology and species interactions within each of these habitats are relatively well understood. However, many of the same plant and animal species live in all of these separate habitats, but the way in which their interactions shift between those habitat types and the consequent community outcomes and patterns have not been experimentally examined.

Menge \& Sutherland $(1976,1987)$ developed a conceptual model predicting how the importance of ecological processes, such as disturbance, competition and predation, vary predictably in response to environmental stress. Some of the basic predictions of their model are that the abundance of basal trophic levels is limited by physical factors at high levels of environmental stress, by predation at low levels of physical stress and by competition at intermediate levels of physical stress. Bertness \& Callaway (1994) extended this model by including facilitation, predicting that positive interactions will be the most important structuring process where physical and biological (predation and/or competition) stress is highest, due to neighbour amelioration of respective stressors. Thus, the background environment is predicted to drive changes in direction and intensity of species interactions along natural stress gradients. The balance between positive and negative interactions has been the topic of several other modelling studies (e.g. Holmgren et al. 1997, Travis et al. 2005) and field studies at local spatial scales, generally within a single habitat (e.g. Menge et al. 1986, Maestre et al. 2003). Despite this interest, no previous studies have tested models of species interactions under differing environmental stresses across large scales that actually span distinct habitat types.

In the present paper we examine how community composition and species interactions shift with differing hydrodynamic stresses (currents and waves) in Narragansett Bay and contribute to formation or maintenance of the distinct habitat types found in this bay. By doing so, we test whether models of species interactions developed at local-scale environmental gradients (Menge \& Sutherland 1987, Bertness \& Callaway 1994) accurately predict the shifting nature of species interactions between different habitats at a landscape scale. Scaling-up from previous work within salt marshes (Bertness \& Ellison 1987, Ewanchuk \& Bertness 2004) and cobble beaches (Bruno 2000), we hypothesised that at landscape scales, the dominant factor structuring vegetation patterns would be physical disturbance where hydrodynamic energy is highest, facilitative interactions where hydrodynamic impact is intermediate, and competitive exclusion where hydrodynamic stress is low. Research was conducted in intertidal habitats common to southern New England and in other semi-protected coastal areas including bare cobble beaches, vegetated cobble beaches, fringing marshes and developed salt marshes. We tested the relationship between hydrodynamic energy and vegetative habitat type at different scales, transplanted several species of forbs (flowering plants, mostly non-woody) and grasses along the entire hydrodynamic gradient, and performed manipulative experiments at extreme ends of the hydrodynamic gradient. Together, these approaches provide evidence that interactions between common plant species shift due to varying environmental stress, and result in the formation of distinct coastal habitat types.

\section{MATERIALS AND METHODS}

Field site. Surveys were conducted in central Narragansett Bay, Rhode Island, USA, and field experiments were located in the same bay in the Narragansett Bay National Estuarine Research Reserve $\left(41^{\circ} 39^{\prime} \mathrm{N}\right.$, $71^{\circ} 21^{\prime} \mathrm{W}$ ). Narragansett Bay is a well-mixed estuary with near oceanic salinity ( 28 to $31 \mathrm{ppt}$ ) and semi-diurnal tides ranging from 0.8 to $2.0 \mathrm{~m}$. Waves within the sheltered bay can exceed $1 \mathrm{~m}$, and are generated by local winds and boat traffic (Bruno 2000). The main wind direction is variable and fluctuates on a daily basis (Zhao et al. 2006). Experimental study sites were selected as representative of the 4 common coastal habitats in Narragansett Bay (Fig. 1). At the most exposed locations, such as headlands, bare cobble beaches dominate. In areas that are apparently sheltered from prevailing winds and wave action, cobble beaches are colonised by the grass Spartina alterniflora with forb communities behind the $S$. alterniflora bed (vegetated cobble beaches). In yet more protected areas, such as embayments, cobble beaches are occupied by $S$. alterniflora beds with grasses such as Spartina patens and Distichilis spicata dominating behind the bed (fringing marsh). Finally, on extremely sheltered shores and behind berms, salt marshes occur. In all of these distinct habitat types (except on the most wave-swept bare cobble beaches), S. alterniflora dominates the low-tidal heights, where it facilitates initial establishment of the community in mid- 
and high-tidal zones. In salt marshes, the facilitative mechanism is the build-up of peat (Bertness 1988), and on cobble beaches it buffers hydrodynamic impact and stabilises the substrate (Bruno 2000). However, the communities occurring behind $S$. alterniflora at midtidal elevations differ considerably between different habitats.

Large-scale coastal vegetative survey and hydrodynamic measurements. A large-scale coastline survey was performed to examine the correlation between coastal habitats and hydrodynamic energy. Approximately $150 \mathrm{~km}$ of coastline within Narragansett Bay was visually surveyed from a boat travelling $5 \mathrm{~km} \mathrm{~h}^{-1}$ within $20 \mathrm{~m}$ of the shoreline. The coastline was categorised as bare cobble beach, vegetated cobble beach, or fringing marsh/salt marsh (Fig. 1). Composite beaches comprised of coarse sand and rocks were grouped with the bare cobble category, and salt marshes fronted by sandy berms were assigned to the saltmarsh category. The length and locations of habitats along the shoreline were recorded using a global positioning system (Trimble 76CS), downloaded into ArcView (ArcGIS 9.1) and depicted on a coastline map. The vegetation survey data were correlated spatially with an average exposure index (AEI), which ranks shoreline wave energy from 1 to 20 based on effective fetch, wind direction and wind speed. This index was calculated previously for $100 \times 100 \mathrm{~m}$ grids in Narragansett Bay (see Kopp et al. 1995 for details). Differences in AEI among all habitat types were calculated using a 1-way analysis of variance (ANOVA). Homogeneity of variances was examined using a Cochran's $C$-test. AEI values were log-transformed to homogenise variances. Post hoc comparisons were done using a Tukey Honest Significant Difference (HSD) test.

To examine a qualitative relationship between habitat types and hydrodynamic forcing at greater spatial resolution, and to verify the large-scale application of the AEI, we deployed 5 dissolution blocks to measure relative differences in water flux at 10 replicate sites of each habitat type: bare cobble beaches, vegetated cobble beaches, fringing marshes and salt marshes (see Thompson \& Glenn 1994, Bruno \& Kennedy 2000 for details on dissolution block technique). Dissolution blocks were glued on 2 layers of mesh, which were pinned to the surface. Blocks were placed intertidally about $10 \mathrm{~cm}$ above the soil surface, at the lower border of the Spartina alterniflora bed, to avoid measuring potential flow energy reduction behind the bed, and were placed at the equivalent tidal heights in the other habitats. Dissolution blocks were only used as a qualitative measure for general hydrodynamic stress to compare between different habitats. The blocks were deployed at the end of April and collected 14 d later. To account for loss of some blocks due to failure of adhesives, 7 locations and 4 blocks for each location were used in statistical analysis. A 2-way nested ANOVA was used to examine differences in block mass loss for each habitat type (with the site replicate nested in habitat type). Homogeneity of variances was tested using a Cochran's $C$-test. Mass loss from the blocks was natural log-transformed to meet assumptions for normality. Post hoc differences among groups were determined using a Tukey HSD test.

Plant survival across gradients. To test where common shoreline plants grew best, size-standardised plant units (phytometers) of 4 common coastal species were transplanted to the 4 habitats (bare cobble beach, vegetated cobble beach, fringing marsh and salt marsh) and their survival was monitored. In each habitat, plants were planted at mid-tidal heights where they are typically found. Individual ramets of the grass Spartina patens, 1 to 2 yr old individuals of the perennial Limonium nashii and seedlings of the

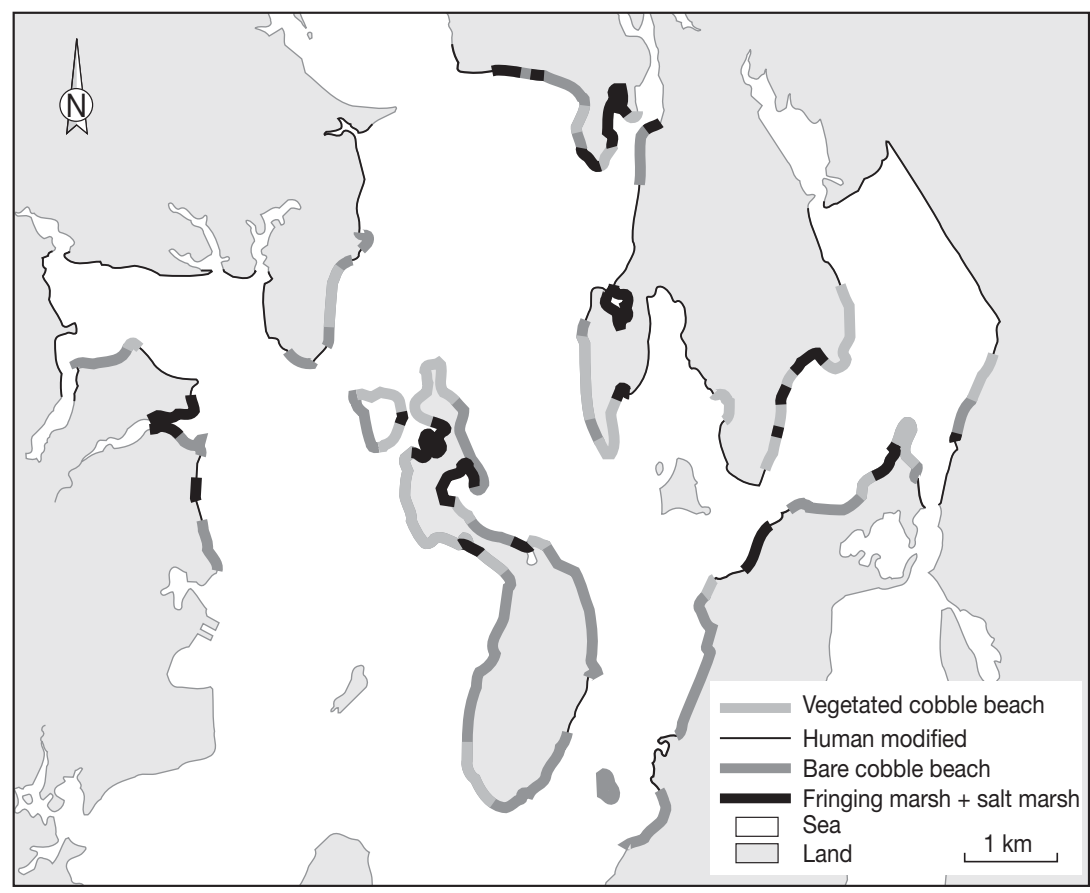

Fig. 1. Survey of coastline habitats in a part of Narragansett Bay (Rhode Island, USA) 
Table 1. Test statistics and p-values for Gehan's Wilcoxon test. To compare between survival of each species (Spartina patens, Suaeda linearis, Salicornia europaea, Limonium nashii) separately in all different habitats, pairwise comparisons were done for all combinations with a value of $\mathrm{p}<0.003$. $\mathrm{sm}$ : salt marsh; fm: fringing $\mathrm{marsh}_{\text {; }} \mathrm{vcb}$ : vegetated cobble beach; bcb: bare cobble beach

\begin{tabular}{|c|c|c|c|c|c|c|c|c|}
\hline \multirow[t]{2}{*}{ Habitats } & \multicolumn{2}{|c|}{ S. patens $(\mathrm{n}=16)$} & \multicolumn{2}{|c|}{ Suaeda $(\mathrm{n}=80)$} & \multicolumn{2}{|c|}{ Salicornia $(\mathrm{n}=320)$} & \multicolumn{2}{|c|}{ Limonium $(\mathrm{n}=16)$} \\
\hline & Test statistic & $\mathrm{p}$ & Test statistic & $\mathrm{p}$ & Test statistic & $\mathrm{p}$ & Test statistic & $\mathrm{p}$ \\
\hline sm-fm & -1.01 & 0.31 & 2.10 & 0.04 & 3.36 & $<0.003$ & 0.63 & 0.53 \\
\hline $\mathrm{sm}-\mathrm{vcb}$ & -1.05 & 0.30 & 5.10 & $<0.003$ & 4.59 & $<0.003$ & 3.00 & $<0.003$ \\
\hline vcb-fm & 0.92 & 0.36 & 4.37 & $<0.003$ & 3.29 & $<0.003$ & 3.02 & $<0.003$ \\
\hline bcb-fm & -4.95 & $<0.003$ & -10.05 & $<0.003$ & -20.31 & $<0.003$ & -4.71 & $<0.003$ \\
\hline bcb-vcb & -2.90 & 0.0037 & -10.67 & $<0.003$ & -17.53 & $<0.003$ & -5.08 & $<0.003$ \\
\hline bcb-sm & -4.74 & $<0.003$ & -9.42 & $<0.003$ & 21.17 & $<0.003$ & -4.82 & $<0.003$ \\
\hline
\end{tabular}

annuals Salicornia europaea and Suaeda linearis were used as phytometers. Four replicates of each species were transplanted into each of 4 replicate sites of each habitat type. All transplants were obtained from nearby field sites. Seedlings, small plants and ramets were planted into $10 \times 10 \mathrm{~cm}$ blocks of peat, where they were watered and allowed to stabilise for 3 to $5 \mathrm{~d}$. Phytometers that survived the stabilisation period were then planted into the different communities, buried flush with the surrounding substrate, and their peat base was secured in place with a galvanised steel garden staple. For the perennials, there was only 1 small plant in each transplant, but for the annuals there were 5 seedlings in the $S$. linearis transplants and 20 seedlings in the $S$. europaea transplants. All plants were planted in May. Survival was recorded bi-weekly for 3 mo. Survivorship for each species was analysed using a survival analysis based on a Gehan's Wilcoxon test. Survival trends were compared among habitat types using pairwise survival test statistics with an adjusted $\alpha$-value of 0.0033 (Bonferroni adjustment: $\alpha$-value of 0.01 divided by 3 , the number of comparisons for each data point) presented in Table 1.

Stabilisation and competition experiments. Based on results from previous studies, we performed 2 experiments to test whether removing communitylimiting variables at both ends of the gradient enabled plant persistence in those habitats. On bare cobble beaches, plants are generally limited by physical stress that can be ameliorated by Spartina alterniflora beds, which buffer hydrodynamic stresses and allow forbs to occur higher on the beach behind the beds (Bruno 2000). In salt marshes, on the other hand, most plants are excluded from the zone above $S$. alterniflora by the competitively dominant Spartina patens (Bertness 1991). To test the generality of these results at our study sites and to test the competitive-exclusion hypothesis in the fringing-marsh habitat, we performed a stabilisation experiment on the bare cobble beach and a competition-removal experiment in the salt marsh. For both experiments we transplanted plants in the same way as described for the transplanting experiment.

The stabilisation experiment was conducted to investigate if substrate instability associated with high hydrodynamic energy limits survival of forb seedlings on bare cobble beaches. Substrate stabilisation was designed to mimic facilitation by Spartina alterniflora beds, which can baffle wave energy and minimise cobble movement. Cobbles were stabilised by securing a piece of hardware cloth (mesh size $1 \times 1 \mathrm{~cm}^{2}$ ) over the cobbles, and plants were transplanted into stabilised areas $(n=9)$ and into adjacent unstabilised control areas (n = 9) (see Bruno 2000 for methods). Three species were used: the perennials Spartina patens and Limonium nashii, and an annual from the cobble beach forb community, Suaeda linearis. For the perennials, 1 plant or stem was used per peat block; for $S$. linearis, 5 seedlings were planted in each peat block. The experiment was initiated in late May 2005, which is a peak period for the emergence of shoreline plants and a time when spring storms are common. After $3 \mathrm{wk}$, the aggregate dry biomass of each species in each plot was taken as a measure of plant performance. Biomass data were compared with a 1-way ANOVA, and homogeneity of variances was verified using a Cochran's $C$-test. Data were $\log (x+1)$ transformed when necessary to meet ANOVA assumptions (Sokal \& Rohlf 1995).

To test the hypothesis that competition with Spartina patens excludes other plants from the higher marsh zones where hydrodynamic stress is benign, competition experiments were performed. Individual ramets of the grass $S$. patens, 1 to 2 yr old individuals of the perennial Limonium nashii, and seedlings of the annuals Salicornia europaea and Suaeda linearis were transplanted to the salt marsh and fringing marsh, into areas from which the dominant grass was experimentally removed (no competition treatments) or into unmanipulated control areas (competition 
treatments). Above-ground biomass of the dominant grasses (predominantly $S$. patens) was removed by manual clipping of $40 \times 80 \mathrm{~cm}^{2}$ areas. Bare plots and controls were replicated 10 times in each habitat, and 1 individual of each of the 4 species was transplanted to each plot. After $3 \mathrm{mo}$, all species were harvested and weighed. Dry biomass per replicate was analysed as a measure of plant performance. Data were analysed using the Mann-Whitney $U$-test for nonparametric data.

\section{RESULTS}

The survey of Narragansett Bay (Fig. 1) revealed that fringing marshes/salt marshes are restricted to areas protected from wave exposure (e.g. like coves and bays) and that bare cobble beach is prevalent on moreexposed shorelines. Differences in the exposure index (AEI) of the 3 habitats (bare cobble beach, vegetated cobble beach and fringing marsh/salt marsh) were significant $\left(F_{2,87}=17.8, \mathrm{p}<0.05\right.$ for all post hoc comparisons), revealing that habitat type is correlated with hydrodynamic stress (Fig. 2A). This relationship was further supported by the dissolution block sampling (Fig. 2B), which revealed significant differences in water movement between vegetative habitat types $\left(F_{3,84}=54.8\right.$ and $\mathrm{p}<0.01$ for all comparisons), except for the difference between bare cobble and vegetated cobble beach. These results imply that community structure is largely influenced by hydrodynamic forces, but that some bare beaches are potentially suitable habitat for Spartina alterniflora colonisation.

The phytometer transplant experiment revealed that, in general, shoreline plant species perform best on cobble beaches where the forb community is naturally found (vegetated cobble beaches; Fig. 3). The 3 forb species all survived best in the vegetated cobble beach habitat, while Spartina patens survived equally well in the vegetated cobble beache, fringing-marsh and salt-marsh habitats. In contrast, there was rapid mortality of all transplanted species on beaches comprised of bare cobble, unless the substrate was experimentally stabilised. At the more wave-protected end of the gradient, Limonium nashii and S. patens persisted through the growing season in the salt marsh and fringing marsh, but Salicornia europaea and Suaeda linearis failed to do so.

In the stabilisation experiment, all 3 species performed better in stabilised plots than in control plots (Limonium nashii: $F_{1,16}=9.4, \mathrm{p}<0.05$, Suaeda linearis: $F_{1,16}=11.3, \mathrm{p}<0.05$ and Spartina patens: $F_{1,16}=6.0$, $\mathrm{p}<0.05$, see Fig. 4). Transplants in the non-stabilised treatment were crushed by cobbles and shell material after 1 single storm event. Of the 3 experimental spe- cies, S. patens was most affected by cobble movement. Of this particular species, no individuals were able to survive in the unstabilised control treatment, whereas some individuals of the other species survived in this treatment (Fig. 4).

In the competition experiment, results differ between salt marsh and fringing marsh (Fig. 5). In the salt marsh, competition suppressed growth of Salicornia europaea ( $Z$-adjusted $=-2.15, \mathrm{p}<0.05$ ) and Spartina patens $(Z$-adjusted $=-2.18, \mathrm{p}<0.05)$, but did not have a detectible effect on Limonium nashii ( $Z$-adjusted = $0.65, \mathrm{p}=0.51$ ) or Suaeda linearis $(Z$-adjusted $=-1.00$, $\mathrm{p}=0.32$ ). For the latter plant species, this appears to be due to high variances, because average biomass was lower in competition treatments. In fringing marsh, all transplant species had significantly higher biomass without competition than those growing with competition (L. nashii: Z-adjusted $=-2.69, \mathrm{p}<0.01$, $S$. europaea: $Z$-adjusted $=-3.86, \mathrm{p}<0.01, S$. linearis: $Z$-adjusted $=-3.16, \mathrm{p}<0.01, S$. patens: $Z$-adjusted $=$ 2.55, p < 0.05).
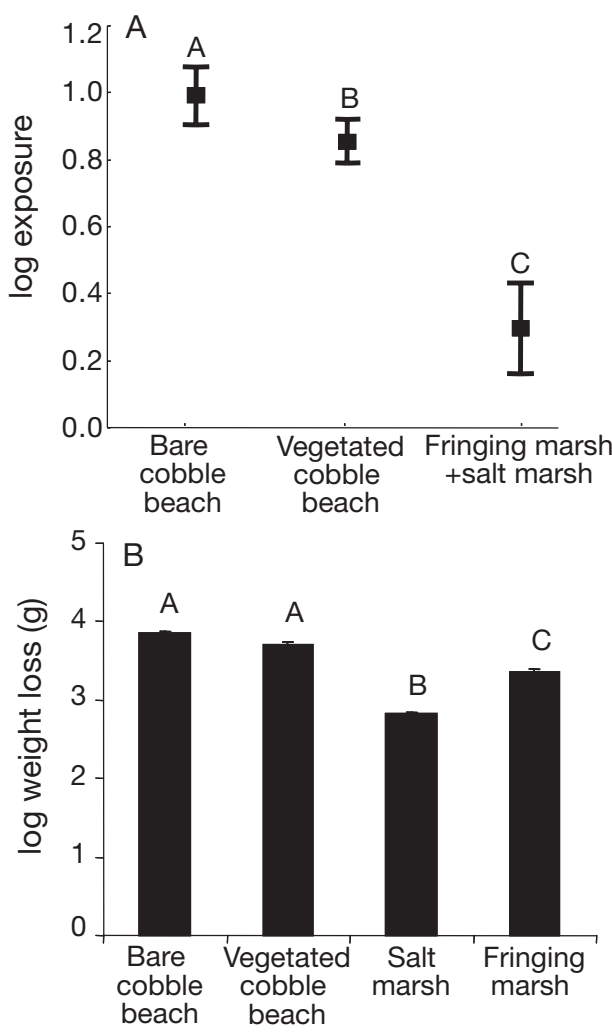

Fig. 2. Relation between hydrodynamic forces and present community established by (A) using the survey of community types along the coast linked with the log of an exposure index and (B) a dissolution block study on different beaches in the bay. Panel A shows differences in exposure of 3 categories of coastal habitat $\left(F_{2,87}=17.8, \mathrm{p}<0.05\right)$ and the letters in Panel B indicate significant differences $\left(F_{3,84}=54.8\right.$ and $\mathrm{p}<0.01)$ 

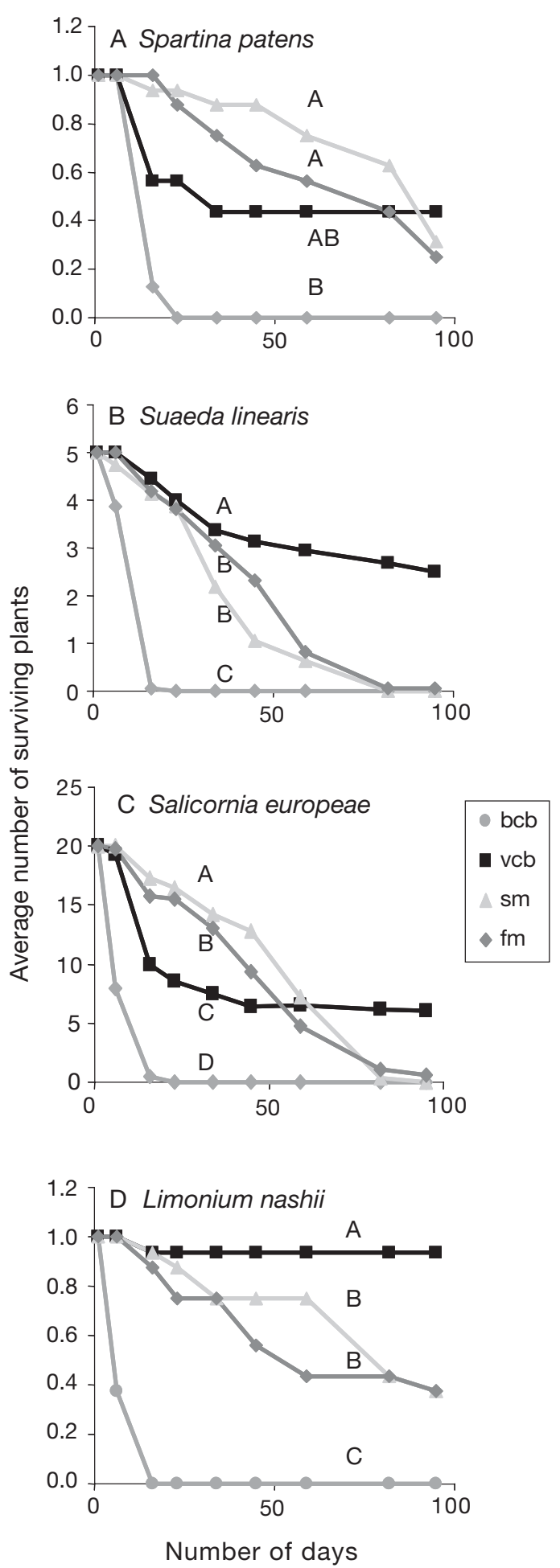

Fig. 3. Survival trends in 4 different community types (bcb: bare cobble beaches; vcb: vegetated cobble beaches; sm: developed salt marshes; fm: fringing marshes) along a hydrodynamic stress gradient of seedlings of 4 different species: (A) Spartina patens $(\mathrm{n}=4)$, (B) Suaeda linearis $(\mathrm{n}=4)$, (C) Salicornia europeae $(\mathrm{n}=4)$, and (D) Limonium nashii $(\mathrm{n}=4)$. Letters indicate significant differences between trends for $\mathrm{p}<0.0033$ (see Table 1 for test statistics)
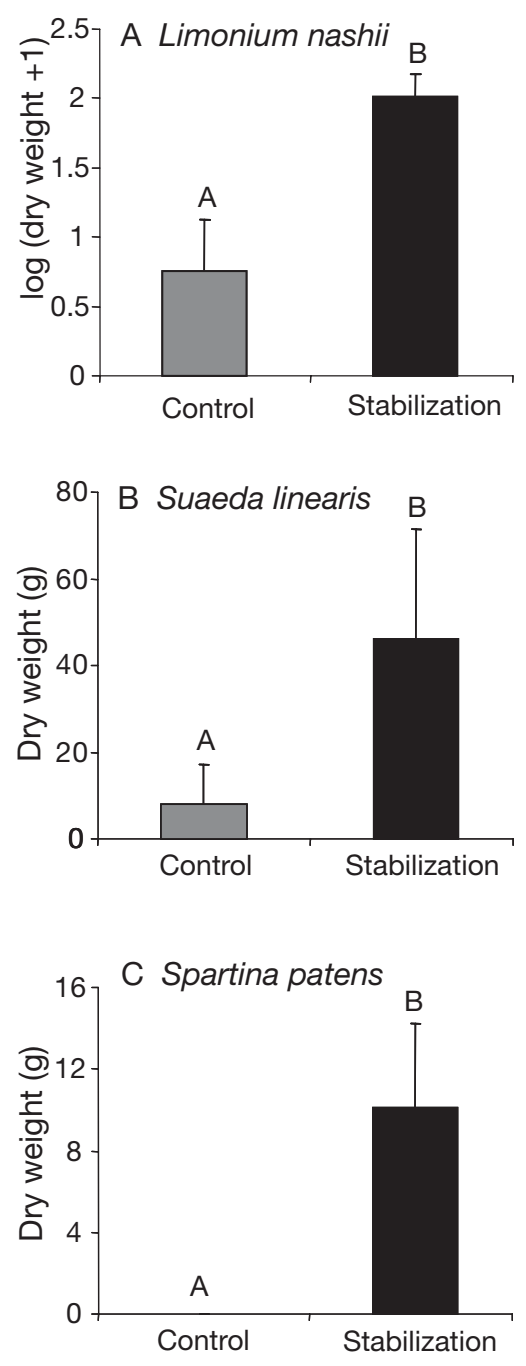

Fig. 4. Final biomass of seedlings in stabilised (black) and control plots (grey) of 3 different species: (A) Limonium nashii $\left(F_{1,16}=9.4, \mathrm{p}<0.05\right)$, (B) Suaeda linearis $\left(F_{1,16}=11.3, \mathrm{p}<0.05\right)$ and $(\mathrm{C})$ Spartina patens $\left(F_{1,16}=6.0, \mathrm{p}<0.05\right)$. Error bars represent standard errors, and letters above bars indicate significant differences for $\mathrm{p}<0.05$

\section{DISCUSSION}

Our results revealed that shifting plant interactions lead to creation of distinct habitat types along wavestress gradients. Interactions shift from primarily facilitative on exposed vegetated cobble beaches to competitive at protected fringing- and salt-marsh sites. At intermediate stress, the competitive dominant from the marsh was relegated to a minor role. As a consequence of this shift in the nature of interspecific interactions, the community assembly mechanisms and organisation of shoreline plant communities vary. 

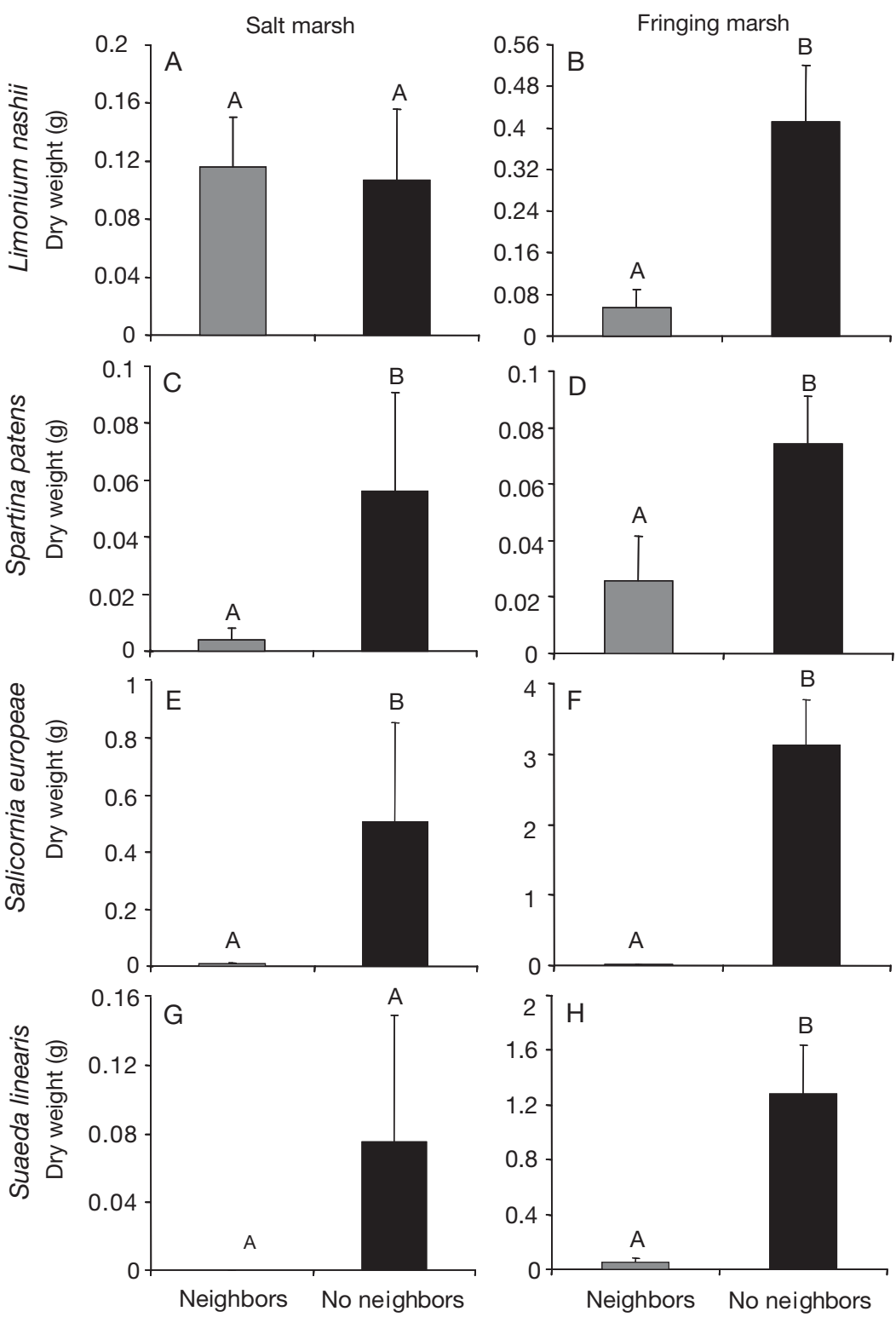

Fig. 5. Final biomass of seedlings in control plots with neighbours (grey) and neighbour removal (black) of 4 different species: (A, B) Limonium nashii (marsh: $Z$-adjusted $=0.65, \mathrm{p}=0.51$; beach: $Z$-adjusted $=-2.69, \mathrm{p}<0.01) ;(\mathrm{C}, \mathrm{D})$ Spartina patens (marsh: $Z$-adjusted $=-2.18, \mathrm{p}<0.05$; beach: $Z$-adjusted $=2.55, \mathrm{p}<0.05$ ); (E, F) Salicornia europeae (marsh: $Z$-adjusted $=-2.15, p<0.05$; beach: $Z$ adjusted $=-3.86, p<0.01$ ); and $(\mathrm{G}, \mathrm{H})$ Suaeda linearis (marsh: $Z$-adjusted $=$ $-1.00, \mathrm{p}=0.32$; beach: $Z$-adjusted $=-3.16, \mathrm{p}<0.01$ ) for 2 different habitats, a protected salt marsh $(\mathrm{A}, \mathrm{C}, \mathrm{E}, \mathrm{G})$ and a fringing marsh developing on a cobble beach $(B, D, F, H)$. Error bars represent standard errors, and letters above bars indicate significant differences for $\mathrm{p}<0.05$

\section{Occurrence of coastal habitats in relation to hydrodynamic stress}

The geology of the coastline dictates the exposure of coastline organisms to waves and currents. In the Narragansett Bay ecosystem, glacial retreat, shoreline ero- sion and sea-level rise have driven the present outline of the land-sea interface (Donnelly \& Bertness 2001). The resulting hydrodynamic context, in turn, determines background environmental stress for interactions among a common suite of halophytic plants and ultimately generates what have always been considered and studied as distinct coastal habitat types. In addition to the extreme variation in coastal exposure between salt marshes and cobble beaches that drives different habitat types, hydrodynamic variation also drives more subtle, yet consistent, differences among cobble beach community types. There are some caveats with using dissolution blocks (Porter et al. 2000). However, we deployed all blocks in similar environments, and have only used the results as a qualitative estimate for hydrodynamic stress. Results from our dissolution blocks coincide nicely with results derived from the exposure index. Salt marshes are found in protected bays where hydrodynamic energy is very low, allowing sediment deposition and peat accretion (Allen 2000). In contrast, higher hydrodynamic stress on exposed coastlines leads to open cobble beaches where substrate instability crushes and abrades emerging vegetation (Bruno 2000). In relatively protected cobble areas where wave energy is consistent enough to create a steep beach slope, yet low enough for some sediment deposition and peat accretion, fringing marshes develop that are similar to salt marshes. However, in fringing marshes, vegetation zones are condensed relative to salt marshes, as the slope of the beach is steep (Bruno 2000). As wave exposure increases on cobble beaches, Spartina patens becomes rare and, instead, a community of forbs develops behind $S$. alterniflora beds. These communities, with intermediate hydrodynamic stresses, are the most diverse communities in our spectrum and can contain up to 11 plant species (Bruno \& Kennedy 2000).

Hydrodynamic stress measured by our dissolution blocks accurately predicted the presence of all of the habitat types described above, except bare cobble and 
vegetated cobble beaches, which it was unable to resolve. The lack of differences between vegetated and non-vegetated cobble beaches may be due to sampling time. We recorded our dissolution block measurements in spring to target the period critical to the emergence of forbs, and may have missed differences that determine the success of Spartina alterniflora among sites in other seasons. An alternative explanation is that $S$. alterniflora colonisation of bare cobble beaches is limited by propagule dispersal and that positive feedbacks promote bed growth and persistence once $S$. alterniflora is established, as suggested by Bruno \& Kennedy (2000). Nevertheless, our analysis of the exposure index (AEI), which does account for seasonal shifts in prevailing winds by integrating conditions throughout the year, revealed differences in exposure between vegetated and nonvegetated cobble beaches.

Once Spartina alterniflora is established, its role as a foundation species and ecosystem engineer facilitates the establishment of plant communities behind (Bruno 2000) and invertebrate communities within (Altieri et al. 2007) the bed. This successional development of the coastal environment ultimately climaxes in salt-marsh systems, unless harsh hydrodynamic conditions prevent the peat accumulation necessary for marsh development. Such an interface between successional species interactions and environmental limitations can lead to 'arrested succession', which is succession terminated by local environmental circumstances (Graham \& Henry 1933). In our study system, the hydrodynamic conditions along the environmental gradient effectively determine prevailing species interactions, which combine with positive feedbacks to generate distinct habitats from a common pool of potential component species. The shorelines are thus hierarchically organised (Altieri et al. 2007), where environmental stress in the form of wave-driven substrate instability determines first where the foundation species $S$. alterniflora can establish, which in turn determines the nature of secondary interactions among the plants facilitated by $S$. alterniflora. Alternative hypotheses for variation in community type across the hydrodynamic gradient, such as seed dispersal, have been examined previously in our study system and have been shown not to limit distributions of shoreline forbs (Rand 2000, Bruno 2002).

\section{Plant response over the whole gradient}

The trade-off between stress tolerance and competitive dominance is a recurring mechanism in the partitioning of species along stress gradients. This general trade-off has determined plant distribution patterns across other coastal gradients, such as tidal elevation (Little \& Kitching 1996) and salinity gradients (Crain et al. 2004), and likely drives species distribution patterns across our hydrodynamic gradient as well. For instance, Spartina patens, the best competitor in the low flow environment of marshes where it forms a monoculture (Bertness 1988, La Peyre et al. 2001), is not able to dominate in the higher stress environment of cobble beaches, regardless of whether S. alterniflora buffers water movement in the low zone. Transplants of $S$. patens experienced high mortality in the Spartina-forb cobble beach and total mortality in the most physically extreme environment. As a result, halophytic forbs that are competitively inferior to $S$. patens in salt marshes (Rand 2000, Ewanchuk \& Bertness 2004) exploit a competitive refuge on cobble beaches in the zone behind $S$. alterniflora beds where hydrodynamic stress is sufficiently buffered. S. patens is likely more susceptible to physical stress and unable to dominate behind $S$. alterniflora beds on cobble beaches, allowing a diverse forb community to proliferate. It seems that coastal forbs and grasses exhibit trade-offs in stress tolerance and competitive ability that determine their distribution across a hydrodynamic stress gradient, resulting in emergence of different habitats. In our system, facilitation by a foundation species drives development of a diverse community under intermediate stress conditions where the competitively dominant species is restricted by physical factors.

\section{Applying models to landscape scales}

Conceptual models that predict shifting outcomes of species interactions along physical stress gradients (Menge \& Sutherland 1987, Bertness \& Callaway 1994, Bruno et al. 2003) have been widely supported by small-scale empirical studies conducted within a given habitat type. For instance, on rocky shores, Ascophyllum nodosum buffers the intertidal community from extreme desiccation stress at high intertidal environments, but interacts neutrally or negatively with species at lower intertidal elevations where desiccation stress is less extreme (Leonard 1999). Similarly, in high alpine systems, positive interactions between plants are more common at stressful high elevations, and competition prevails at more physically benign lower elevations (Callaway et al. 2002). Also, in semi-arid Mediterranean grasslands, the facilitative effects of grasses on shrubs increase with stress (Maestre et al. 2003). Together these studies lend support for shifting species interactions across environmental stress gradients on local scales or within a single habitat, whereas the present study provides evidence that these concep- 
tual predictions can be generalised to landscape-scale gradients of environmental stress that span several distinct habitat types.

Our study is among the first to integrate facilitation theory with the intermediate disturbance hypothesis, which assumes that species diversity is highest with intermediate physical stress (Connell 1979). For example, in our system, facilitation by a foundation species drives a highly diverse community at intermediate stresses. The need to integrate models of community organisation with theories of diversity and productivity has been previously suggested (Bruno et al. 2003) and will allow the development of a more complete picture of ecosystem functioning and organisation. In this respect, our present findings imply a broader application of general community ecology theories: ecosystems and regions that have historically been considered as consisting of independent habitats can be unified by a common mechanistic framework.

Acknowledgements. We thank K. Bromberg, K. Becklin, S. Bertness, A. Littlefield and C. Holdredge for their dedication in the field, and F. Rossi for help with statistical analyses. The Rhode Island Sea Grant, NOAA NERRS Graduate Research Fellowships and the Schure-Beijerinck-Popping Fund (Project No. SBP/JK/2005-39) provided financial support of the research. The experiments performed during this study complied with the current laws of the USA. This is publication 4173 of the NIOO-KNAW Netherlands Institute of Ecology.

\section{LITERATURE CITED}

Allen JRL (2000) Morphodynamics of Holocene salt marshes: a review sketch from the Atlantic and southern North Sea coasts of Europe. Quat Sci Rev 19:1155-1231

Altieri AH, Silliman BR, Bertness MD (2007) Hierarchical organization via a facilitation cascade in intertidal cordgrass bed communities. Am Nat 169:195-206

Bertness MD (1988) Peat accumulation and the success of marsh plants. Ecology 69:703-713

Bertness MD (1991) Interspecific interactions among high marsh perennials in a New England salt-marsh. Ecology 72:125-137

Bertness MD (1999) The ecology of Atlantic shorelines. Sinauer Associates, Sunderland, MA

Bertness MD, Callaway R (1994) Positive interactions in communities. Trends Ecol Evol 9:191-193

Bertness MD, Ellison AM (1987) Determinants of pattern in a New England salt-marsh plant community. Ecol Monogr 57:129-147

Bertness MD, Gaines SD, Hay ME (2000) Marine community ecology. Sinauer Associates, Sunderland, MA

Bruno JF (2000) Facilitation of cobble beach plant communities through habitat modification by Spartina alterniflora. Ecology 81:1179-1192

Bruno JF (2002) Causes of landscape-scale rarity in cobble beach plant communities. Ecology 83:2304-2314

Bruno JF, Kennedy CW (2000) Patch-size dependent habitat modification and facilitation on New England cobble beaches by Spartina alterniflora. Oecologia 122:98-108

Bruno JF, Stachowicz JJ, Bertness MD (2003) Inclusion of facil- itation into ecological theory. Trends Ecol Evol 18:119-125 Callaway RM, Brooker RW, Choler P, Kikvidze Z and 9 others (2002) Positive interactions among alpine plants increase with stress. Nature 417:844-848

Connell JH (1979) Intermediate-disturbance hypothesis. Science 204:1345

Crain CM, Silliman BR, Bertness SL, Bertness MD (2004) Physical and biotic drivers of plant distribution across estuarine salinity gradients. Ecology 85:2539-2549

Donnelly JP, Bertness MD (2001) Rapid shoreward encroachment of salt marsh cordgrass in response to accelerated sea-level rise. Proc Natl Acad Sci USA 98:14218-14223

Ewanchuk PJ, Bertness MD (2004) Structure and organization of a northern New England salt marsh plant community. J Ecol 92:72-85

Graham HW, Henry LK (1933) Plant succession at the borders of a Kettle-Hole Lake. Bull Torrey Bot Club 60:301-315

Holmgren M, Scheffer M, Huston MA (1997) The interplay of facilitation and competition in plant communities. Ecology 78:1966-1975

Kennedy CW, Bruno JF (2000) Restriction of the upper distribution of New England cobble beach plants by waverelated disturbance. J Ecol 88:856-868

Kopp BS, Doherty AM, Nixon SW (1995) A guide to site selection for eelgrass restoration projects in Narragansett Bay, Rhode Island. Technical Report to RIDEM Marragansett Bay Project. University of Rhode Island, Providence, RI

La Peyre MKG, Grace JB, Hahn E, Mendelssohn IA (2001) The importance of competition in regulating plant species abundance along a salinity gradient. Ecology 82:62-69

Leonard GH (1999) Positive and negative effects of intertidal algal canopies on recruitment and survival of barnacles. Mar Ecol Prog Ser 178:241-249

Little C, Kitching JA (1996) The biology of rocky shores. Oxford University Press, Oxford

Maestre FT, Bautista S, Cortina J (2003) Positive, negative, and net effects in grass-shrub interactions in Mediterranean semiarid grasslands. Ecology 84:3186-3197

Menge BA, Sutherland JP (1976) Species-diversity gradients - synthesis of roles of predation, competition, and temporal heterogeneity. Am Nat 110:351-369

Menge BA, Sutherland JP (1987) Community regulation: variation in disturbance, competition, and predation in relation to environmental-stress and recruitment. Am Nat 130:730-757

Menge BA, Lubchenco J, Gaines SD, Ashkenas LR (1986) A test of the Menge-Sutherland model of community organization in a tropical rocky intertidal food web. Oecologia 71:75-89

Porter ET, Sanford LP, Suttles SE (2000) Gypsum dissolution is not a universal integrator of 'water motion'. Limnol Oceanogr 45:145-158

Rand TA (2000) Seed dispersal, habitat suitability and the distribution of halophytes across a salt marsh tidal gradient. J Ecol 88:608-621

Sokal RR, Rohlf FJ (1995) Biometry. WH Freeman and Company, New York

Thompson TL, Glenn EP (1994) Plaster standards to measure water motion. Limnol Oceanogr 39:1768-1779

Travis JMJ, Brooker RW, Dytham C (2005) The interplay of positive and negative species interactions across an environmental gradient: insights from an individual-based simulation model. Biol Lett 1:5-8

Zhao L, Chen C, Cowles G (2006) Tidal flushing and eddy shedding in Mount Hope Bay and Narragansett Bay: an application of FVCOM. The School for Marine Science and Technology, New Bedford, MA 